DOI: http://dx.doi.org/10.18764/2358-4319.v11n2p151-171

\title{
Discutindo processos de aprendizagem e de escolarização de crianças em tratamento para câncer e atendidas na classe hospitalar
}

Jucélia Linhares Granemann de Medeiros ${ }^{1}$

\section{RESUMO}

No Brasil, o serviço de classe hospitalar vem a cada dia expandindose e estruturando-se. Atualmente, encontra-se vinculado à área de Educação Especial, tendo como principal meta a continuidade do processo escolar de crianças e adolescentes, matriculados ou não na educação infantil, no ensino fundamental e médio, hospitalizados e/ou em tratamento de saúde. Nesse processo, conforme diversos estudiosos, apoiados em Vygoskty (2001, 2003, 2005), para crianças e adolescentes, incluindo nesse cenário, educandos com câncer, em condições de saúde e/ou em tempos diversos de hospitalização, clientela essa também contemplada com esse atendimento, o maior desafio nesse período é sua inclusão nas diferentes atividades e vivências acadêmicas, próprias de sua idade, respeitando, portanto, suas condições físicas, cognitivas, sociais e emocionais, oriundas/ resultantes dessa fase do tratamento. A classe hospitalar, nesse sentido, pode colaborar paralelamente, no período, para adaptar e trabalhar com suas possíveis dificuldades e/ou deficiências surgidas em seu processo de aprendizagem, o que facilitará, após alta hospitalar, o seu retorno à escola. Em geral, observa-se que esse atendimento é realizado praticamente em quase todos os Estados brasileiros. Algumas estruturações ou adequações, tanto físicas como de funcionamento, necessitam ser revistas, a fim de melhor atender e/ou corresponder aos objetivos propostos pelo atendimento.

Palavras-chave: Classe hospitalar. Aprendizagem. Escola.

1 Doutora em Educação pela Universidade Federal de Mato Grosso do Sul. Pós-Doutora em Educação pela Universidade Federal do Espirito Santo. Docente da Universidade Federal de Mato Grosso do Sul, Campus de Três Lagoas (UFMS/TL). E-mail: juclia313@yahoo.com.br 


\section{A debate of process of learning and schooling of children in cancer treatment attended in a hospital class}

\section{ABSTRACT}

In Brazil, the hospital class service is every day expanding and structuring themselves. Currently, it is linked to special education, having as the main goal the continuity of the school process of children and adolescents, registered or not in early childhood education, primary and secondary education, hospitalized and/or in health care. In this process, as many scholars, supported by Vygoskty $(2001,2003,2005)$ for children and adolescents, including in this scenario, students with cancer, in health and/or at different times of hospitalization clientele that are also contemplated with this service, the biggest challenge in this period will be included in the different activities and academic experiences, of their own ages, respecting thus their physical, cognitive, social and emotional conditions, arising / resulting from this phase of treatment. The hospital class, in this purport, can work in parallel, to adapt and work with their possible difficulties and / or deficiencies that arise in the learning process, which will facilitate, after discharge, their return to school. In general, it is observed that this procedure is carried out practically in almost all Brazilian states. Some structuring or adjustments, both physical and operational, need to be revised in order to better meet and / or correspond to the objectives proposed by the service.

Keywords: Hospital class. Learning. School.

\section{Discutiendo los procesos del aprendizaje y de la escolarización de niños en tratamiento para el cáncer en la clase hospitalaria}

\section{RESUMEN}

En Brasil la práctica de la clase hospitalaria se expande y se estructura a cada día. Actualmente se encuentra vinculada con el área de la Educación Especial, y presenta como reto principal la continuidad del proceso escolar de niños y adolescentes, inscritos o no en la educación preescolar, en la enseñanza fundamental y en la media, hospitalizados y/o en tratamiento. En ese proceso, según diversos estudiosos, apoyados en Vygotsky $(2001,2003,2005)$, para niños y 
adolescentes, inclusos en este panorama niños enfermos de cáncer, con distintas condiciones de salud y tiempo de internación, los cuales son también usuarios de esta modalidad de enseñanza, el gran desafío en este periodo es la inclusión en las distintas actividades y experiencias académicas, propias de cada edad, para que se pueda tratar con respeto sus condiciones físicas, cognitivas, sociales y emocionales, pues que las mismas surgen de esa fase del tratamiento. En este sentido, la clase hospitalaria puede contribuir paralelamente en cada una de estas fases, adaptando y trabajando con las posibles dificultades y/o deficiencias que puedan surgir en el proceso de aprendizaje, lo que va a tornar más fácil, después de la baja médica, su regreso a la escuela. Algunas estructuraciones o adecuaciones, fiscas y del funcionamiento, necesitan una revisión, para que mejor puedan atender y/o corresponder a los objetivos propuestos por el atendimiento.

Palabras clave: Clase hospitalaria. Aprendizaje. Escuela.

\section{Introdução}

A internação hospitalar em decorrência de algumas doenças pode ser necessária em determinada fase da vida do adulto ou da criança, levando-os a permanecer em hospitais por um período curto, longo e/ou em diversas internações intermitentes. Nesse cenário, o câncer é uma das patologias que mais acometem a criança na infância e tem prevalência e reflexos bastante significativos quando se relaciona a sua saúde e sua consequente qualidade de vida.

Sob esse prisma, o entendimento desse processo por familiares e profissionais que a atende na escola, torna-se essencial ao bom andamento e desenvolvimento de um ensino diferenciado e atento às suas reais condições e necessidades. Nessa direção, esse artigo foi elaborado, objetivando por meio de um estudo bibliográfico, retratar, dificuldades e perspectivas pedagógico-educacionais relacionadas a essa clientela, seja em uma escola ou em um atendimento acadêmico especializado hospitalar.

Iniciando a discussão, o Instituto Nacional de Câncer- INCA (2008), explica que os tumores pediátricos são de mais rápido crescimento; no entanto, respondem melhor aos tratamentos e são considerados de bom prognóstico. Do câncer infantil, a leucemia é o tipo mais 
frequente - particularmente a leucemia linfoide aguda (LLA) -, além do linfoma não hodgkin, os tumores do sistema nervoso, tumores ósseos, neuroblastoma, tumor de wilms, tumores de partes moles, histiocitose, tumores germinativos e o retinoblastoma (GRAACC, 2010). ${ }^{2}$

Perina, Mastellaro e Nucci (2008) acrescentam que, há vinte anos, a cura do câncer significava sucesso terapêutico; porém, hoje, a verdadeira cura exige alcançar o potencial biológico, intelectual, psíquico, emocional e social que acompanha a criança submetida ao tratamento. Assim, é necessário um acompanhamento multiprofissional em todas as fases, desde o diagnóstico, durante e após o tratamento, incluindo o atendimento escolar por intermédio da "classe hospitalar".

Nessa modalidade de ensino, o professor adaptará a programação em andamento nas classes originais dos alunos. Os alunos internados serão temporários da educação especial por estarem afastados do universo escolar e/ou diante de situações de adoecimento provocadas pelo câncer, de tratamento longo e agressivo. Cohen e Melo (2010) sinalizam que esse processo faz com que a criança se perceba ainda membro de uma classe e fortalece o desejo de pertencimento social; e o afastamento prolongado ou ausências esporádicas da escola não produzirão tantos prejuízos acadêmicos.

2 Tipos mais comuns de câncer em crianças, segundo GRAACC (2010, grifo do autor):

LEUCEMIA - É o câncer mais comum na infância. Leucemias têm origem na medula óssea, o tutano dos ossos, onde é normalmente produzido o sangue. Manifesta-se com dor nos ossos ou nas articulações, palidez, manchas roxas, sangramentos, febre, abatimento, etc. A leucemia é diagnosticada através do mielograma, exame do sangue de dentro do osso. Existem vários tipos de leucemia: Leucemia Linfoide Aguda (LLA), Leucemia Mieloide Aguda (LMA), Leucemia Mieloide Crônica (LMC) e Leucemia Linfoide Crônica (LLC - só em adultos). Além da medula óssea, as leucemias podem também acometer os testículos, endurecendo-os, e o líquor (líquido da espinha), provocando dores de cabeça e vômitos. As leucemias podem ter índices de cura de até $80 \%$ quando tratadas com quimioterapia. Em alguns casos, podem-se indicar também radioterapia e transplante de medula. TUMORES DO SISTEMA NERVOSO CENTRAL - Os tumores do sistema nervoso central, cérebro e cerebelo são os tumores sólidos (que não leucemias e linfomas) mais frequentes em crianças. Os sintomas mais comuns são dor de cabeça e vômitos pela manhã, tontura e perda do equilíbrio. Qualquer criança com persistência desses sintomas deve ser examinada por um médico neurologista, além de realizar tomografia ou ressonância nuclear magnética do crânio. $O$ diagnóstico do tipo exato de tumor é feito durante a cirurgia. Os tumores benignos são tratados apenas com cirurgia. Para os tumores malignos são, em geral, necessárias quimioterapia e radioterapia.

LINFOMA NÃO HODGKIN - Mais frequente no sexo masculino, ocorre principalmente entre os 4 e 8 anos de idade. Atinge qualquer parte do corpo, principalmente tórax e abdome. Quando o linfoma é na barriga, do tipo Brukit, pode causar parada de evacuações e dor na barriga. Como o tratamento é feito com quimioterapia, não deve ser realizada cirurgia para a retirada do intestino. Quando o linfoma é no tórax, pode causar tosse ou falta de ar. O diagnóstico dos linfomas depende de biópsia do tumor. Quando diagnosticado precocemente, os índices de cura são de $80 \%$. 
Nesse período, explicam Carvalho e Ceccim (1997), o universo da criança, que antes era composto da família, dos amigos e da escola, ganha mais dois componentes: o hospital e a doença. Nesse momento, ela pode entrar em conflito provocado pelo ambiente, onde passa a ser paciente, sendo alvo de agressões ao próprio corpo, o qual se encontra em fase de descoberta, e "a hospitalização, em determinadas situações, constitui-se num risco igual ou maior aos que da própria doença os originou" (CECCIM; CARVALHO, 1997, p. 27).

Para Freitas e Ortiz (2005, p.36), o estar hospitalizado pode gerar-Ihe insegurança, estresse e "traumas, às vezes profundos, dependendo da intensidade e da estrutura de sua personalidade". Outras ansiedades, como impotência, dependência, mudança da imagem corporal (dependendo da doença) e medo da morte, também surgem na criança internada, pois deixa de ter direitos sobre o próprio corpo e se vê separada abruptamente da vida que, dia a dia, construía e reconstruía sua identidade. Além desses aspectos, conforme Lima e Natel (2010), podem ser desencadeados atrasos no crescimento e desenvolvimento psicomotor e geradas complicações psíquicas, como depressão e comportamentos regressivos, dependendo do tempo de internação e/ou do seu quadro. Appel (2000) relembra que, dependendo do estágio da doença que a criança está tratando, são inúmeros os medicamentos uti-

NEUROBLASTOMA - Ocorre geralmente em crianças com menos de 5 anos. Os locais mais comuns são abdome, tórax e pescoço, perto da coluna vertebral. Pode afetar o fígado, ossos e a medula óssea. Todos os tumores do abdome podem ser confundidos com verminose. Se a criança tem aumento da barriga que não melhora, deve-se procurar um médico para avaliação. Os tumores que crescem próximos da coluna vertebral podem causar fraqueza nas pernas, dor e perda do controle da eliminação de fezes e urina. Se o tratamento não for iniciado a tempo, a criança pode ficar com paralisia definitiva. Para diagnosticar o neuroblastoma é necessário, em geral, realizar uma biópsia do tumor, ou seja, retirar um pedaço pequeno através de cirurgia para que um médico patologista possa vê-lo no microscópio. Os neuroblastomas são tratados com cirurgia e quimioterapia. Em alguns casos, indica-se radioterapia e transplante de medula.

TUMOR DE WILMS - É um tumor frequente na infância, geralmente aparece antes dos 5 anos de idade. $O$ tumor de Wilms nasce nos rins, manifestando-se como uma massa no abdome. A criança pode ainda apresentar sangue na urina, dores abdominais e pressão alta. $O$ exame mais indicado para o diagnóstico é o ultrassom. $O$ tratamento é cirurgia, em que se retira o rim comprometido, seguido, em geral, de quimioterapia e, em alguns casos, de radioterapia. A cura está estimada em torno de $90 \%$ dos casos.

SARCOMAS DE PARTES MOLES - São tumores que podem ocorrer em músculos, gordura e articulações. Afetam tanto crianças, quanto adolescentes e adultos. Existe um aumento progressivo, inchaço no local do tumor e, em geral, há dor e a pele pode ficar vermelha. Os sarcomas podem ocorrer na cabeça, no pescoço, na área genital, nos braços e nas pernas. Em adolescentes, pode localizar-se na região dos testículos, provocando aumento do escroto, sendo confundido com hérnias. O paciente não pode ter vergonha de contar seu problema ao médico! Para diagnosticar os sarcomas é muito importante 
lizados que podem ocasionar sérios problemas de regressão no sistema nervoso central.

Nessa situação, a criança sofre também, pois a hospitalização, mais do que a problemática de saúde em si, gera falta às aulas. Isto pode contribuir para o aumento de suas dificuldades em acompanhar os conteúdos escolares, levando à probabilidade de defasagem no ano do ciclo em que ela vinha cursando. Por vezes, a hospitalização pode inviabilizar sua matrícula em uma escola, interferindo na percepção que a criança tem de si, ou seja, de sua autoestima, não deixando possibilidades de desenvolvimento nos aspectos físico, social e intelectual (FONSECA, 2003).

Esse quadro, para Wallon (2007), não significa a lei única do seu futuro, seja em uma constituição biológica saudável ou doente. No decorrer de toda a sua evolução, as demandas sociais e culturais estarão influenciando e alterando toda essa dinâmica de desenvolvimento, que, para o autor, é dependente das experiências oferecidas pelo meio e do grau de apropriação que o sujeito faz delas. Portanto, uma avaliação na elaboração de um currículo, que comporte intervenções educacionais adequadas, assume a existência do mundo extra-hospitalar - a escola como agenciadora de processos de aquisição de aprendizagem, desen-

que um médico experiente em câncer realize uma biópsia a fim de examinar o tumor no microscópio. O tratamento dos sarcomas é feito, em geral, com cirurgia e quimioterapia. TUMORES ÓSSEOS São mais frequentes em adolescentes. Quase sempre a criança conta que teve uma batida, que causou dor, mas a dor não vai embora. O local mais comum é logo acima ou logo abaixo do joelho. A pele pode ficar vermelha e quente e, quando o tumor cresce, é possível ver também um inchaço no local. Esses sintomas podem ser confundidos principalmente com infecções ou dores de crescimento. Para diagnosticálo, é importante fazer raio $\mathrm{X}$ do local doloroso, e um médico ortopedista, com bastante experiência em câncer, deve realizar uma biópsia com agulha, sem cortar a pele. Os tipos mais comuns de tumores ósseos malignos são osteossarcoma e Sarcoma de Ewing. O tratamento é feito com cirurgia e quimioterapia. O diagnóstico precoce aumenta as chances de cura para até $70 \%$.

RETINOBLASTOMA - Afeta os olhos e geralmente ocorre antes dos 4 anos de idade. A principal manifestação é um reflexo brilhante no olho doente, parecido com o brilho que apresentam os olhos de um gato quando iluminados à noite. As crianças podem ainda ficar estrábicas (vesgas), ter dor nos olhos ou perder a visão. Alguns retinoblastomas são hereditários.Seoutras pessoas dafamíliajátiveramotumor, as crianças devemserexaminadas por um oftalmologista experiente desde a hora do nascimento para que o diagnóstico seja o mais precoce possível. Os retinoblastomas são diagnosticados por médicos experientes através do exame do fundo de olho, com a pupila bem dilatada. Em geral, não se deve realizar biópsias. Os tumores pequenos podem ser tratados com métodos especiais, que permitem que a criança continue a enxergar normalmente. Nos casos adiantados, o olho pode precisar ser retirado e a criança pode precisar de quimioterapia e/ou radioterapia. DOENÇA DE HODGKIN - É um tumor que acomete gânglios e baço mais frequente em 
volvimento de competência intelectual e interação entre seus pares. Isto compõe uma nova qualidade de vida, entrecruzando sentidos e construindo sentidos para ressignificar o adoecimento.

Nesse atendimento, a criança deve ser trabalhada integralmente de modo a dispor de um atendimento que corresponda a seu ciclo vital de desenvolvimento, de aprendizagem e escolarização, levando-a ao desejo de cura (FONSECA, 2003). Enquanto o aluno estiver em sala de aula do hospital, pode ser desvinculado das restrições do tratamento médico. O professor oferecerá um currículo que lhe dê condições de adquirir conhecimentos e aptidões para exercer o autocuidado com sua doença (VASCONCELLOS, 2000), subsidiando, paralelamente, a aceitação do seu processo de internação e de adoecimento.

Nesse sentido, a formação do professor deve ser de forma constante de interação e reciprocidade entre a formação inicial e a formação em exercício. Além disso, deve ter um caráter mediador entre o aluno e o conteúdo, com questionamentos que o levem à reflexão e à apreensão desse objeto de conhecimento. O professor, desse modo, precisa avaliar sua prática e estar aberto a novos conhecimentos e técnicas (AROSA; SCHILKE, 2008), para que a doença não interrompa o processo de desenvolvimento infantil. Entretanto, as restrições físicas e/ou psicossociais decorrentes da doença e do tratamento podem retardar esse desenvolvimento (FONSECA, 1995, 1998). Deve-se envolver nesse trabalho a cura orgânica com o mínimo de prejuízo da capacidade de crescimento e desenvolvimento da criança e a cura psicossocial, para que ela se man-

\footnotetext{
adolescentes. A maioria dos casos começa com adenomegalias, «ínguas» que vão crescendo no pescoço, nas axilas ou na região inguinal. A criança pode apresentar febre prolongada e perda de peso. O diagnóstico do Linfoma de Hodgkin éfeito através de biópsia de um gânglio aumentado detamanho. Otratamento éfeito com quimioterapia eradioterapia. Atualmente, em cada 100 crianças tratadas adequadamente, 85 ficam completamente curadas. HISTIOCITOSE Apesar de não ser câncer, a histiocitose é uma doença tratada por oncologistas, pois muitas vezes as crianças precisam de quimioterapia para melhorar. Pode apresentar-se como uma dermatite seborreica de difícil tratamento, otite com pus nas orelhas que vai e volta, lesões na pele, fígado e baço aumentados, lesões nos ossos e anemia.

TUMORES GERMINATIVOS - São tumores do ovário ou testículos, raros na infância. Os tumores de ovário podem causar dores abdominais, geralmente crônicas, puberdade precoce (crescimento dos seios e aparecimento de pelos antes do tempo) e tumorações palpáveis. Os meninos com testículos que não desceram para a bolsa escrotal (criptorquidia) devem ser vigiados com ultrassom, pois a incidência de câncer é 20 a 40 vezes maior nesses casos. O sinal de alerta é o aumento da bolsa escrotal, confundido muitas vezes com hérnia. O diagnóstico é feito na cirurgia em que se retira o tumor. Nos meninos é importante ainda que a cirurgia seja realizada pela barriga e não abrindo o escroto. O tratamento é realizado com cirurgia e quimioterapia."
} 
tenha intelectual, social, emocional e fisicamente adaptada às funções pertinentes a sua idade.

\section{Classe hospitalar}

\section{Conceituação e Estruturação das Classes Hospitalares}

Fonseca (1999a) refere que o acompanhamento escolar ao aluno hospitalizado favorece sua construção subjetiva de estabilidade de vida não apenas como elaboração psíquica da enfermidade e hospitalização, mas, principalmente, como continuidade e segurança dos laços sociais da aprendizagem (relação com colegas e relações de aprendizagens mediadas por professor), com um currículo que lhe permita referir à existência de uma "escola no hospital" ou de uma "classe escolar" em ambiente hospitalar.

Sua sistemática de atuação no Brasil é semelhante à de outros países (FONSECA, 1999b), consolidada por convênios entre as Secretarias de Educação e a de Saúde. É necessário, no entanto, entender que a classe hospitalar possui especificidades, acionando-se propostas estimuladoras ao conhecimento e à aprendizagem, oferecendo assim uma abordagem específica com atividades educativo-escolares e lúdico-escolares.

Nesse caminhar, o profissional deve aproveitar cada momento vivenciado como "ganchos para dinamizar ou reestruturar a atividade, [...] abrindo uma nova janela para o interesse do aluno e seu desempenho frente às atividades em desenvolvimento" (FONSECA, 2003, p. 27). A autora acrescenta que, no ambiente hospitalar, o contato com a escola é o lado saúdavel de estar doente. Essa interferência gera energia positiva no organismo da criança, o que colabora para uma recuperação mais rápida da condição de saúde, conforme estudo de Fonseca e Ceccim (1999), que evidenciou associação significativa entre a frequência às aulas no hospital e a redução em $30 \%$ nos dias de internação. A realidade nacional mostra ainda que a clientela infantil nos hospitais se concentra em crianças com menos de seis anos (educação infantil) e faixa etária entre seis e dez anos (séries iniciais) (NASCIMENTO, 2004; FONSECA, 2000).

Ainda, os aspectos como a rotatividade dos alunos, a rotina diária, o fluxo e a dinâmica das internações fazem com que os professores pensem em estratégias adequadas às exigências e necessidades, con- 
templando a criança hospitalizada (AROSA; SCHILKE, 2008). A educação que se processa não pode ser identificada como um simples depósito de conhecimentos, mas sim um suporte psicopedagógico, pois ameniza para a criança a condição de doente, mantendo-a integrada nas atividades da escola e da família, apoiada pedagogicamente por profissionais capacitados para ampará-la.

Nessa perspectiva, o educando se desenvolve, porém necessita de um espaço acolhedor e seguro e de um tempo satisfatório para processar suas aprendizagens, que conduzam ao desenvolvimento. Também devem ser dadas atividades nutritivas para o desenvolvimento. Afinal, o educando necessita de desenvolvimento (LUCKESI, 2005).

Na classe hospitalar, afirmam Funghetto, Freitas e Oliveira (1999), o desenvolvimento dos conteúdos ou temáticas acontecerá conforme as fases de desenvolvimento da criança a ser atendida e a presença de crianças com idades mistas possibilita uma nova prática pedagógica. Sob esse prisma, o trabalho da classe hospitalar, ao mesmo tempo em que foca os objetivos vinculados aos conteúdos a serem desenvolvidos, deve ser adequado às necessidades e aos interesses dos alunos. Deve prever alternativas para que, caso aconteça um imprevisto em sala de aula, tais momentos possam ser aproveitados como se fossem "deixas", ousando-se a ir com os alunos por caminhos que, embora não estivessem planejados, provoquem mudanças no seu processo de desenvolvimento e aprendizagem (FONSECA, 2003). Isto poderá Ihe propiciar maior capacidade de agir sobre o mundo, acomodar-se a ele e diferenciar-se qualitativamente (LURIA, 2008).

Nesses princípios, Ceccim (1999) defende que a classe hospitalar deve apoiar-se em propostas curriculares educativo-escolares, e não em propostas de educação lúdica, recreativa ou de ensino para a saúde, diferenciando-se das Salas de Recreação, das Brinquedotecas e dos Movimentos de Humanização Hospitalar pela Alegria ou dos Projetos Brincar é Saúde. Por isso, a oferta de atividades recreativas e/ou lúdicas não deve substituir a atenção pedagógico-educacional, pois seu potencial de intervenção é mais específico e volta-se às construções cognitivas e à construção do desenvolvimento psíquico, o reencontro de sua identidade e o desenvolvimento das inteligências múltiplas.

Já Ceccim e Carvalho (1997, p. 83) entendem que "o espaço do aprender, na situação hospitalar, deve ter uma preocupação com o lúdico maior que na situação escolar". Cunha (1994, p. 25) explica que "atra- 
vés de jogos e brincadeiras, a criança pode aprender novos conceitos, adquirir informações e até mesmo superar dificuldades de aprendizagem, configurando-se como outras ferramentas convenientes para a aprendizagem da criança em situação hospitalar".

Nesse instante, a promoção de atividades que favorecem o envolvimento da criança internada em brincadeiras, principalmente aquelas que promovem a criação de situações imaginárias, tem função pedagógica primordial. Ressalta-se que nem todo brinquedo é fantasia, há vários elementos inseridos nele, inclusive o histórico. A brincadeira pode ser uma criação do sujeito, mas também pode ser tendência do meio, não apenas uma mera transposição da realidade (VYGOTSKY; LURIA; LEONTIEV, 2001).

Góes (2000) acrescenta que se pode derivar a ideia de que esse tipo de brincadeira tem sua gênese naquilo que é vivenciado e conhecido, embora a atividade imaginativa envolvida não seja apenas recordar, mas reelaborar experiências, combinando e criando novas realidades, de acordo com necessidades, condições e preferências. Porém, nesse processo, mesmo inovando, a criança leva em conta as regras, em termos do que é pertinente a um papel social, do que é apropriado ao agir com as coisas e de como os acontecimentos podem se organizar. Em qualquer circunstância, o jogo permite à criança modelar as relações entre as pessoas. Ele é influenciado pelas atividades humanas e pelas relações entre as pessoas, e o conteúdo fundamental é o homem - a atividade dos homens e as relações com os adultos. Ao mesmo tempo, ele exerce influência sobre o desenvolvimento psíquico da criança e do adolescente e sobre a formação de sua personalidade (ELKONIN, 1987).

Nesses aspectos, o desenvolvimento do aluno hospitalizado ocorre mesmo em um ambiente não tão familiar, porém necessário nesse momento, para sanar ou amenizar seu sofrimento perante a enfermidade. Nessa interlocução, acabará tendo um contato muito próximo com os professores hospitalares. Isto faz com que as atividades escolares no hospital tenham regularidade e se assemelhem aos moldes das escolas oficiais, embora, em alguns momentos, as crianças ou os adolescentes se sintam indispostos e não possam acompanhar as programações escolares (PAULA, 2002, p. 13). Independentemente do tempo de permanência deles no hospital, o atendimento na classe hospitalar os ajuda a se desvincular das restrições desse ambiente e pode ter um significado importante para o seu processo de desenvolvimento e aprendizagem. 
Processos educativos da criança com câncer na classe hospitalar

Crianças internadas com câncer nos hospitais têm faixas etárias diferenciadas; o quadro clínico é variável; a medicação a ser utilizada é diferente de uma para outra; os aspectos emocionais do processo de internação podem variar de criança para criança; a aceitação da doença é vista de diversas maneiras tanto pela família como pelo paciente; e o tempo de internação é variável, entre outros aspectos. No hospital, professores e alunos são "sujeitos de experiências sociais" que vão reproduzindo e elaborando a própria cultura. Trazem suas histórias pessoais, vivências e marcas que se entrelaçam nas diversas relações estabelecidas, que se inserem no contexto social, político e econômico e dos quais são parte. Assim, além de adquirir a linguagem produzida por essa sociedade, desenvolve o pensamento, os afetos e os sentimentos.

Vygotsky, Luria e Leontiev (2001) colocam que, conforme o homem se apropria das diversas linguagens, que servem como mediadoras de sua relação com o meio, ele passa a ter acesso a um conjunto de significados historicamente produzidos, que integram a sua cognição. Entretanto, um ser ativo, ao se apropriar dessas linguagens, desses significados presentes em uma determinada cultura, ressignifica-os, conferindo-Ihes outro sentido (individual) que coexiste com o significado sócio-histórico.

Nessa interlocução, Leontiev (1978, p. 69) verifica que "a criança no curso de seu desenvolvimento, penetra ativamente no mundo das relações humanas que a rodeia, assimilando (primeiro de forma muito concreta e real) as funções sociais das pessoas, as normas e as regras de comportamento socialmente elaboradas". Ela torna-se consciente das relações sociais estabelecidas, o que a leva a uma mudança na motivação de sua atividade; nascem novos motivos, conduzindo-a à reinterpretação de suas ações anteriores.

Vygostky (2003) observa também que a força principal do desenvolvimento vem das contradições internas entre as novas experiências que se colocam para o aprendiz e os meios que ele dispõe para responder a elas. A interação social com pessoas mais "experientes" culturalmente é que provocará saltos qualitativos para a linguagem e o pensamento verbal mais estruturado na criança. A partir desses pressupostos, pode-se dizer que o desenvolvimento humano é um processo. 
A partir do contexto de suas falas, de suas experiências, de seus diálogos é que o conhecimento é construído como um bem social efetivamente partilhado e posto a serviço da transformação. Segundo a visão sócio-histórica, o desenvolvimento se dá pelas trocas dos sujeitos com o mundo e, nesse sentido, a escola com a família exerce um papel relevante na formação da identidade social e pessoal da criança e do adolescente. $\mathrm{Na}$ escola desempenham um papel ativo no cotidiano, definindo o que a escola é, limite e possibilidade, em um diálogo, o conflito constante com sua organização. Nesses aspectos, sejam temporários ou duradouros, todos os grupos têm objetivos determinados: a composição depende desses mesmos objetos, do mesmo modo a repartição dos cargos referentes a ele, as relações dos membros e, se necessário, a sua hierarquia.

Vygotsky (2001) argumenta que as pessoas significam o seu processo de interação social pela construção de sentidos individuais e pelo uso de significados sócio-históricos e que um dos instrumentos privilegiados que possibilitam essa apreensão e a materialização das significações é, ainda, a linguagem. Com a evolução do uso da palavra, a criança orienta arbitrariamente sua atenção para determinados atributos, e os sintetiza, simboliza o conceito abstrato e opera com ele como lei suprema entre todas aquelas criadas pelo pensamento humano (VYGOTSKY, 2005), ampliando e desenvolvendo todo o seu potencial cognitivo. À medida que a criança vivencia novas experiências e situações de utilização de palavra, seus processos institucionais de abstração se generalizam e progridem (GÓES, 2000).

O exercício da linguagem implica, também, a possibilidade de expressar o que se pensa e como se pensa. Igualmente, observa-se que o surgimento e o desenvolvimento da linguagem implicam, também, a necessidade de se expressar e podem provocar o enfrentamento de situações práticas, que impulsionem e motivem o sujeito a falar.

Somente depois, quando da conversão em fala interior, ela vem organizar o pensamento da criança, ou seja, torna-se uma função mental interna (VYGOTSKY, 2003). É por meio do processo de interiorização que ocorre uma transformação da atividade que, agora, é dirigida e controlada pela própria criança. Esse processo de fora para dentro vai modificar totalmente o comportamento infantil, estruturando a sua consciência.

Nessa circunstância, a fala, na criança, é tão importante quanto à ação para atingir um objetivo e faz parte de uma mesma função psicológica complexa. A fala e o uso dos signos incorporados são um 
comportamento humano. Toda a função de desenvolvimento da fala na criança aparece duas vezes: primeiro, no social e, depois, no individual. O aprendizado será algo novo na criança e no seu desenvolvimento. É um processo de incorporação e de apropriação, pelo sujeito, de valores, conhecimentos - conceitos -, ideias e práticas produzidas e organizadas historicamente na sociedade e na cultura (GÓES, 2000).

Essa possibilidade de avaliação e alteração no desempenho de uma criança pela interferência de outra é fundamental na perspectiva sócio-histórica cultural. Dessa forma, não há zona de desenvolvimento individual. Vygostky $(2003)^{3}$ indica extrema importância à interação social na construção das funções psicológicas humanas.

A mediação da aprendizagem não se dá sozinha, por uma simples tarefa de ensinar. Para que a criança se aproprie do conhecimento, é necessária a interferência de vários elementos, e essa interlocução é levada por meio do desafio da atividade, que, por si só, não tem muito significado. A escola e a família também estão ligadas à zona de desenvolvimento proximal (ZDP), principalmente no que diz respeito às crianças com câncer que necessitam de estímulos e intervenções a todo o momento para minimizar ou evitar quaisquer atrasos ou défices, sejam na criança saudável, hospitalizada ou em tratamento de saúde.

No ambiente hospitalar também não há outra prática como a curricular, que é indissociável da avaliação e do planejamento. Não é permitido o processo educativo em ações pedagógicas rigidamente planejadas a priori sem a participação dos atores envolvidos nesse processo. É preciso referir, nesse momento, que tal pressuposto vale para o hospital e para a escola. Além disso, planejamento de ensino é o processo que envolve a atuação concreta dos educadores no cotidiano de seu trabalho pedagógico, envolvendo em todas as suas ações e situações a permanente interação entre os educadores e educandos (PADILHA, 2007).

Nesse circuito, devem-se planejar ações para que o currículo trabalhado abranja as questões ligadas à identidade do aluno e ao con-

3 Vygotsky (2003), ao referir sobre o pressuposto da origem social da cognição, mostra a indissociabilidade entre interação social e os processos de ensino-aprendizagem e desenvolvimento, e diferencia esses dois níveis como ZDP: a distância entre o nível de desenvolvimento real, que se costuma determinar pela solução independente de problemas, e o nível de desenvolvimento potencial, determinado pela solução de problemas sob a orientação de um adulto ou em colaboração com companheiros mais capazes. Nesse contexto, direcionado pelas relações interpessoais, as quais não podem ser medidas, a ZDP refere-se, conforme o autor, à solução de problemas que a criança não vai resolver de forma independente. Trata-se das funções que estão em processo "embrionário" e que tornarão funções consolidadas, estabelecidas no seu nível de desenvolvimento real. 
texto hospitalar, compondo a fase investigativa do processo de aprendizagem, a partir da qual serão desenvolvidos os projetos articulados e os conteúdos encaminhados pela escola de origem do aluno. Para Arosa e Schilke (2008), rompe-se o paradigma da grade curricular que encarcera blocos de conteúdos sem considerar os anseios dos alunos que vivenciam experiências diferenciadas no espaço hospitalar.

Ao compreender o significado da escolaridade como elemento fundamental para o processo de recuperação e cura desde o diagnóstico, o professor e a equipe de profissionais de saúde detêm condições de demonstrar que o atendimento pedagógico-educacional no ambiente hospitalar colabora para que a criança não se sinta presa no hospital e possa melhorar a sua compreensão sobre o ambiente hospitalar (FONSECA, 2003). Nesse caso, não se pode pensar em uma educação especializada que regule a ação educativa desenvolvida no hospital, pois sua base é escolar. A ação educativa desenvolvida nesse espaço tem orientação de um pedagógico escolar. Isso, todavia, não significa uma transposição direta de toda e qualquer prática educativa desenvolvida na escola para o interior do hospital.

Porto (2007) destaca que essa aprendizagem possui uma função integradora, e está diretamente relacionada ao desenvolvimento psicológico, denotando as possibilidades de interação e adaptação da pessoa à realidade ao longo da vida, sofrendo múltiplas influências de fatores ambientais e individuais.

O bombardeio medicamentoso prescrito nas terapêuticas e a ausência de desafios cognitivos decorrentes das contingências da reclusão hospitalar podem promover regressão de várias áreas do sistema nervoso central, causando distúrbios de aprendizagem (FREITAS; ORTIZ, 2001).

Diante disso, certamente a criança sofrerá consequências de ordem emocional, pois a adaptação ao meio hospitalar é longa e complicada, pois "muitas vezes, no hospital, por condições clínicas, a situação exige isolamento protetor. No isolamento o indivíduo se encontra, de certa forma, 'preso' a um local onde existem regras e condutas normatizadas" (FUNGHETTO, 1998, p. 58).

Esse isolamento é discutido por essa autora como um sentimento de prisão, pois a criança é submetida às regras e normas da instituição, ou do hospital, além de o contato familiar ser limitado. Há necessidade de se rever a forma que hoje hegemoniza a organização escolar e problematizar a mediação pedagógica, as práticas curriculares e avaliativas, 
produzindo uma reflexão sobre sua pertinência e apresentando alternativas de transformação.

Nesse processo, também a escola de origem poderá contribuir para suavizar a transição do aluno de casa para o hospital e vice-versa. Esse processo pode ser facilitado pelas autoridades educacionais locais em colaboração com os serviços de saúde mental e de assistência social do hospital, conforme previstos nas estratégias e orientações para essa modalidade educacional.

Tais profissionais devem transcender os aspectos médicos, pois, sem uma visão abrangente das relações da criança com as figuras significativas (família, escola, hospital), o êxito do tratamento pode ficar comprometido, além de acarretar prejuízo escolar imediato e futuro até mesmo naquelas crianças que possuem bom desempenho intelectual (VYGOSTKY, 1997). Dessa maneira, o autor aposta no abandono de uma pedagogia hospitalar-medicamentosa, que vê a aprendizagem e o desenvolvimento sob uma perspectiva puramente biológica, por uma pedagogia criativamente positiva, por meio de uma educação social.

Prega-se, então, uma pedagogia mais construtiva, mais humana, voltada para uma educação social, buscando as capacidades dos sujeitos, compartilhando uma ideia em meio aos diversos programas no campo da saúde e da educação e ao crescente número de pessoas envolvidas na atenção de crianças de que o risco para os processos de aprendizagem e desenvolvimento da criança não está atrelado apenas às fragilidades físicas, sendo necessárias as apostas nas interações sociais, educacionais e vínculos afetivos precoces e constantes.

Nesse contexto, González Rey (2005) propõe que se deve evitar a implementação de modelos educacionais que priorizem os fatores biológicos vistos como mais relevantes na determinação da saúde, da doença e do desenvolvimento dos indivíduos, desconsiderando-se, comumente, suas peculiaridades psicossociais e subjetivas, onde podem estar algumas pistas para elaboração de sentido ou campos de inteligibilidade, que contribuem para o entendimento e a intervenção em práticas estimuladoras de aprendizagem e desenvolvimento.

Essa intervenção faz com que a criança mantenha rastros que a ajudam a recuperar seu caminho e garantir o reconhecimento de sua identidade. $\mathrm{O}$ incentivo à aprendizagem e escolarização, nos primeiros meses ou anos de vida, pode fazer do hospital uma agência educacional para a criança desenvolver atividades que a ajudam a construir um 
percurso cognitivo, emocional e social. Essa mediação deve compor um novo quadro de qualidade de vida, entrecruzando e construindo sentidos para ressignificar o adoecimento e suas limitações, estabelecer ritmos próprios, de aprendizagem e desenvolvimento (FREITAS; ORTIZ, 2001).

O desenvolvimento da saúde, no âmbito educativo e institucional, é um desafio atual dos sistemas educacionais e hospitalares. A preocupação pela saúde no campo educativo passa pelo desenvolvimento das instituições, já que estas devem ter uma função educativa que estaria chamada a ocupar um lugar essencial na promoção e prevenção de saúde e de educação, em todos os aspectos do sujeito, estando bastante interligada com a constituição da subjetividade social que a caracteriza e de relevante papel para a sociedade (GONZÁLEZ REY, 2005).

Ao retornar à escola nesse período, são também comuns nas crianças com câncer as diversas dificuldades. Por isso é importante que se realize pesquisa sobre sua evolução neuropsicológica, pois isso afeta a motivação e o interesse à adaptação e à aprendizagem, além da integração social com seus pares (APPEL, 2000).

Algumas vezes, quando a criança com câncer chega à escola, ela traz alguns efeitos colaterais do tratamento/internação que, em geral, é longo e invasivo. Por suas características, não pertence ao grupo de alunos especiais, constituídos de algum tipo de deficiência visual, auditiva ou intelectual. Geralmente, ela é antiga aluna da escola e agora, vitimada por uma doença, necessita de cuidados especiais, transitórios e distintos conforme a fase de tratamento.

Sobre isso, Vygotsky (2005) refere que um possível defeito ou problema físico desafiará qualquer tipo de organismo, pois mina suas atividades e age como uma força negativa. Por outro lado, o defeito ou a inabilidade age como um incentivo para aumentar o desenvolvimento de outras funções no organismo, pois ele desperta o organismo para redobrar atividade, que compensará o defeito e superará a dificuldade.

Apesar de o organismo possuir essa capacidade de superação, esta só se realizará a partir da interação e da contribuição de fatores ambientais, pois o desenvolvimento se dá no entrelaçamento de fatores externos e internos. Assim, todo e qualquer defeito ou inabilidade poderá se converter no ponto de partida e na força propulsora do desenvolvimento psíquico, da aprendizagem e da personalidade da criança, pois, conforme o autor, se origina de estímulos para a formação da compensação ou da superação (VYGOTSKY, 2003). 
Nos casos em que os tratamentos originam efeitos colaterais provenientes de medicações, como a autoimagem afetada, os movimentos motores limitados fazem com que o aluno não se sinta apto a enfrentar a sociedade; com isso, os familiares devem respeitar seu momento e deixá-lo livre para que esse momento chegue de forma tranquila, sem pressões.

Referente à lei geral da compensação, segundo Vygotsky (2003), aplica-se da mesma forma ao desenvolvimento dito "normal" e ao "complicado", sendo esse princípio de muita valia na compreensão sobre a realização de intervenções realizadas com famílias e instituições ou serviços responsáveis por essa criança. Por isso, o autor sugere que a atenção seja focalizada no ambiente social e cultural, podendo mediar relações significativas entre a criança e o meio, de modo que ela tenha acesso ao conhecimento e à cultura.

A interação social nesse processo amplia o universo de cada um; estimula o conflito e a percepção de teses, antíteses e a busca da síntese, ainda que seja mais precária nesse período e mais acentuada na criança perante suas condições físicas e emocionais vividas no momento (VYGOTSKY; LURIA; LEONTIEV, 2001).

A reintegração ao espaço escolar do educando, temporariamente impedido de frequentá-lo por motivo de saúde, deve levar em consideração alguns aspectos, como: o desenvolvimento da acessibilidade e da adaptabilidade; a manutenção do vínculo com a escola durante o período de afastamento por meio da participação em espaços específicos de convivência escolar previamente planejados (sempre que houver possibilidade de deslocamento); momentos de contato com a escola por meio de visita dos professores ou colegas do grupo escolar e dos serviços escolares de apoio pedagógico (sempre que houver a possibilidade de locomoção, mesmo que esporádica); garantia e promoção de espaços para acolhimento; escuta e interlocução com os familiares dos educandos durante o período de afastamento; preparação ou sensibilização dos professores, funcionários e alunos para o retomo do educando à convivência escolar e gradativo aos espaços de estudos sistematizados.

\section{Considerações finais}

Nesse processo, a criança passa a ser concebida como alguém com aptidão para o desenvolvimento, sujeita a programas que maxi- 
mizem suas potencialidades em um ato intencional de dirimir os danos causados pela hospitalização. Em contrapartida, o cuidado para que a criança não se sinta insegura e excluída no retorno à escola é fundamental para não acarretar um atraso no desenvolvimento da aprendizagem (FREITAS; ORTIZ, 2005).

Nesse contexto, a atuação de professores e demais profissionais da educação deve levar em conta a hospitalização infantil. Sentimentos de angústia e temor, vivenciados pelas crianças a serem acompanhadas, podem estar presentes nas dificuldades de aprendizagem, já que, para ocorrer sucesso nela, é necessário um equilíbrio entre os fatores biológico, cognitivo, social e emocional (LIMA; NATEL, 2010). Nesse processo, a intervenção do outro é bastante significativa para a aprendizagem e para o desenvolvimento (VYGOSTKY, 2001).

Finalizando, observa-se que nesse processo, por mais que se busque estruturar e, efetivamente, conhecer as necessidades reais da criança com câncer, ainda tanto nas áreas educacionais e de saúde, verifica-se a existência de certa insuficiência de teorias e estudos, o que gera, no Brasil, o desconhecimento dessa modalidade de atendimento, tanto no sentido de implementar ações que estimulem a continuidade da escolaridade, àquelas crianças que requerem hospitalização, como para no sentido de ampliar a atenção na área de saúde, potencializando melhor seu processo de tratamento e os cuidados que lhes são prestados.

Nesse panorama, sugere-se a ampliação e/ou a implantação de centros de estudos que trabalhem diretamente com projetos e eventos específicos, relacionados à temática, tendo como foco principal, conscientizar e orientar autoridades e profissionais que atuem com essa clientela, tanto no hospital como na escola regular, visando a proporcionar a essas crianças, essa educação mais integral e de qualidade.

\section{Referências}

APPEL, S. Siempre es tiempo de aprender. Declarado do Interés Educativo. Mansilla, Argentina; Buenos Aires, Capital Federal: Ministerio del Interior Subsecretaria de Relaciones con la Comunidad; Ministerio de Cultura y Educacion de la Nación, 2000.

AROSA, A. C.; SCHILKE A. L. Quando a escola é no hospital. Niterói, RJ: Intertexto, 2008. 
BRASIL. Ministério da Saúde. Instituto Nacional de Câncer. Particularidades do câncer infantil. 2008. Disponível em: <http://www. inca.gov.br/conteudo_view>.asp?id=349>. Acesso em: 10 maio 2011.

CECCIM, R. B. Classe hospitalar: encontros da educação e da saúde no ambiente hospitalar. Pátio Revista Pedagógica, Porto Alegre, v. 3, n. 10, p. 41-44, 1999.

CECCIM, R. B.; CARVALHO, P. R. A. Crianças hospitalizadas: atenção integral como escuta a vida, Porto Alegre: UFRGS, 1997.

COHEN, R. H. P.; MELO, A. G. da S. Entre o hospital e a escola: o câncer em crianças. Estilos clin., São Paulo, v. 15, n. 2, p. 306-325, dez. 2010.

CUNHA, N. H. S. Brinquedoteca: um mergulho no brincar. São Paulo: Maltese, 1994.

ELKONIN, D. Sobre el problema de la periodización del desarrollo psíquico en la infancia. In: DAVIDOV, V.; SHUARE, M. (Orgs.). La psicología evolutiva y pedagógica en la URSS (antologia). Moscou: Progresso, 1987. p. 125-142.

FONSECA, E. S. A situação brasileira do atendimento pedagógicoeducacional hospitalar. Revista Educação e Pesquisa, São Paulo: Universidade de São Paulo, v. 25, n. 1, p. 117-129, jan./jun. 1999a.

- Atendimento pedagógico-educacional de bebês especiais no ambiente hospitalar. Temas sobre Desenvolvimento, São Paulo, v. 9, n. 49, p. 9-15, 2000.

Atendimento pedagógico-educacional para crianças e jovens hospitalizados: realidade nacional. In: REUNIÃO ANUAL DA SOCIEDADE BRASILEIRA PARA O PROGRESSO DA CIÊNCIA, 50, 1998, Natal. Resumos... Natal, RN: SBPC, p. 513, jul. 1998.

. Atendimento pedagógico-educacional para crianças e jovens hospitalizados: realidade nacional. Revista Integração, Brasília: MEC/ SEESP, ano 9, n. 21, p. 31-39, 1999b.

- Educador em plantão: aulas em hospitais asseguram continuidade dos estudos e desempenham papel fundamental na recuperação de alunos internados (entrevista). Revista Educação, v. 6, n. 7, p. 18-22, 2003. 
. Young children's distress during radiological examinations.

Thesis. Institute of Education, University of London and The Department of Pediatric Radiology, The Great Ormond Street Children's Hospital, London, 1995.

FONSECA, E. S.; CECCIM, R. Atendimento pedagógico-educacional hospitalar: promoção do desenvolvimento psíquico e cognitivo da criança hospitalizada. Temas sobre Desenvolvimento, São Paulo, v. 7, n. 42, p. 24-36, 1999.

FREITAS, S. N.; ORTIZ, L. C. M. Classe hospitalar: caminhos pedagógicos entre saúde e educação. Santa Maria: Editora UFSM, 2005.

. Classe hospitalar: um olhar sobre sua práxis educacional. Revista Brasileira de Estudos Pedagógicos, Brasília, DF, v. 82, n. 2000/2002, p. 70-77, jan./dez. 2001.

FUNGHETTO, S. S. A doença, a morte e a escola para a criança com câncer: um estudo através do imaginário social. Dissertação (Mestrado em Educação) - Universidade Federal de Santa Maria, Santa Maria, 1998.

FUNGHETTO, S. S.; FREITAS, S. N.; OLIVEIRA, V. F. Classe hospitalar: uma vivência através do lúdico. Pátio, Porto Alegre, ano 3, n. 10, p. 45-47, 1999.

GÓES, M. C. R. A abordagem micro genética na matriz histórico-cultural: uma perspectiva para o estudo da constituição da subjetividade. Cadernos Cedes, Campinas, n. 50, p. 9-25, 2000.

GONZÁLEZ REY, F. L. O sujeito que aprende: desafios do desenvolvimento do tema aprendizagem na psicologia e na prática pedagógica. In:TACCA, M. C. V. R. Aprendizagem e trabalho pedagógico. Campinas: Alínea, 2005.

GRAACC-Grupo de Apoio ao Adolescente e à Criança com Câncer. O câncer infantil: tipos e principais tratamentos. 2010. Disponível em: $\quad$ https://www.graacc.org.br/o-cancer-infantil/tipos-e-principaistratamentos.aspx>. Acesso em: 25 maio 2017.

LEONTIEV, A. N. O desenvolvimento do psiquismo. Lisboa: Livros Horizonte, 1978.

LIMA, M. C; NATEL, M. C. A psicopedagogia e o atendimento pedagógico hospitalar. Rev. psicopedag., São Paulo, v. 27, n. 82, p. 127-139, 2010. 
LUCKESI, C. C. Avaliação da aprendizagem na escola: reelaborando conceitos e recriando a prática. 2. ed. rev. Salvador: Malabares Comunicação e Eventos, 2005.

LURIA, A. R. Desenvolvimento cognitivo. São Paulo: Ícone Editora, 2008.

NASCIMENTO, F. F. A atuação e o atendimento pedagógico hospitalar: um novo caminho na educação. Monografia (Especialização em Psicopedagogia)- Universidade Cândido Mendes, Rio de Janeiro, 2004.

PADILHA, P. R. Planejamento dialógico: como construir o projeto político-pedagógico da escola. São Paulo: Cortez, 2007.

PAULA, E. M. A. T. de. Crianças e professores em hospitais: aprendizes especiais na diversidade dos contextos hospitalares. In: ENCONTRO NACIONAL DE DIDÁTICA E PRÁTICA DE ENSINO. Igualdade e diversidade na educação. 11., 2002, Goiânia. Anais eletrônicos... Goiânia, maio 2002.

PERINA; E. M.; MASTELLARO, M. J.; NUCCI, N. A. G. Efeitos tardios do tratamento do câncer na infância e na adolescência. In: CARVALHO, V. A (Org.). Temas em Psico-oncologia. São Paulo: Summus, 2008. p. 496-504.

PORTO, O. Psicopedagogia institucional: teoria, prática e assessoramento psicopedagógico. São Paulo: Wak Editora, 2007.

VASCONCELLOS, S. M. F. A psicopedagogia hospitalar para crianças e adolescentes. Apresentado na Semana da Psicopedagogia. Fortaleza: Universidade Estadual do Ceará, 2000.

VYGOTSKY, L. S. A formação social da mente. São Paulo: Martins Fontes, 2003.

. Pensamento e linguagem. Trad. Jefferson Luiz Camargo. 3. ed. São Paulo: Martins Fontes, 2005.

Psicologia pedagógica. São Paulo: Martins Fontes, 2001.

VYGOTSKY, L. S.; LURIA, A. R.; LEONTIEV, A. N. Linguagem, desenvolvimento e aprendizagem. São Paulo: Ícone/EDUSP, 2001.

WALLON, H. A evolução psicológica da criança. São Paulo: Martins Fontes, 2007.

Recebido em julho/2017

Aceito em abril/2018 